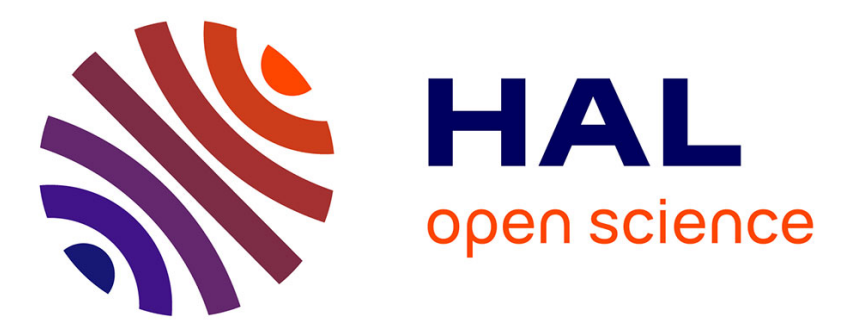

\title{
Investigations of the Dynamic Strength Variations in Metals
}

K. Baumung, G. Kanel, S. Razorenov, D. Rusch, J. Singer, A. Utkin

\section{To cite this version:}

K. Baumung, G. Kanel, S. Razorenov, D. Rusch, J. Singer, et al.. Investigations of the Dynamic Strength Variations in Metals. Journal de Physique IV Proceedings, 1997, 07 (C3), pp.C3-927-C3932. 10.1051/jp4:19973156 . jpa-00255445

\section{HAL Id: jpa-00255445 https://hal.science/jpa-00255445}

Submitted on 1 Jan 1997

HAL is a multi-disciplinary open access archive for the deposit and dissemination of scientific research documents, whether they are published or not. The documents may come from teaching and research institutions in France or abroad, or from public or private research centers.
L'archive ouverte pluridisciplinaire HAL, est destinée au dépôt et à la diffusion de documents scientifiques de niveau recherche, publiés ou non, émanant des établissements d'enseignement et de recherche français ou étrangers, des laboratoires publics ou privés. 


\title{
Investigations of the Dynamic Strength Variations in Metals
}

\author{
K. Baumung, G.I. Kanel*, S.V. Razorenov*, D. Rusch, J. Singer and A.V. Utkin* \\ Forschungszentrum Karlsruhe, P.O. Box 3640, 76021 Karlsruhe, Germany \\ * Russian Academy of Sciences, Institute of Chemical Physics, Chernogolovka 142432, Russia
}

\begin{abstract}
A line-imaging laser Doppler velocimeter has been employed to investigate the uniformity of strength properties of materials at load duration of $\sim 10^{-7} \mathrm{sec}$ or less. The shock load pulses were generated by a pulsed highpower proton beam facility. More or less noticeable spatial variations of the spall strength were found in such different materials as coarse-grain cast magnesium and molybdenum single crystals. In the case of magnesium, the variations of the tensile strength are governed by grain boundaries. In the single crystals, small reductions of the spall strength were accompanied by a decreasing acceleration of the fracture process.
\end{abstract}

Résumé. Un vélocimetre laser à résolution spatiale monodimensionelle a été utilisé pour l'étude des variations locales des propriétés mécaniques des matériaux auxqueis sont appliquées des charges d'une durée de $10^{-7} \mathrm{~s}$ ou moins. Les charges impulsives sont générées par un faisceau de protons pulsé à haute puissance. Des différences plus ou moins notables de la résistance mécanique ont été constatées sur des échantillons aussi đifférents que du magnésium moulé à gros grains et du molybdène monocristallin. Dans le cas du magnésium, les variations de la résistance sont gouvernées par les joints de grains. Dans les monocristaux, de petites réductions de la résistancé furent accompagnées d'une évolution initiale des fractures plus lente.

\section{INTRODUCTION}

The dynamic tensile strength of materials at load durations of microseconds or less is studied by analyzing spall phenomena under shock pulse action [1]. During the dynamic fracture process, many microvoids or microcracks more or less simultaneously undergo nucleation, growth, and coalescence in a volume of material to form a failed or spalled region [2]. Large overstresses even near the ultimate tensile strength can be reached under these conditions due to the high rate of stress application [3]. The amount of activated damage nucleation sites sharply increases with increasing tensile stress because smaller defects get involved.

Two ways to investigate the spall phenomena are mostly used now. Detailed information about mechanisms of the fracture process is obtained by performing microscopic posttest examinations of spall samples [2], while instrumental measurements made during shock-wave loading provide the most accurate data about fracturing stresses under spalling. As has been shown earlier $[4,5]$, the spal] pulse in the free-surface velocity profile can be observed only if the damage rate is in a certain proportion to the expansion rate at unloading in the incident compression pulse. The slope of the spall pulse front incicates the acceleration of the fracture process. Thus, the free-surface velocity histories contain information not only about the spall strength, but also about the macrokinetics of damage evolution. The resistance to dynamic fracture is known to be sensitive to the material structure. The spall strength depends on the load direction relative to the texture of the material [5], the spall strength of metal single crystals exceeding that of polycrystalline samples by a factor of $\sim 2$ to $3[3,5]$.

The line imaging velocimeter technique developed recently [6] provides the capability to record simultaneously the velocity histories in many points along a metsuring line on the sample surface in 
fracture initiation and growth. The objective of the study presented in this paper is a first estimation of the potential of this kind of measurements in the investigation of the dynamic fracture. With this goal, experiments with polycrystalline and monocrystalline samples of magnesium and molybdenum have been performed. It is clear, that we should be able to see some variations in the fracture only in tests with a scale close to that of the nonuniformity of the material. This is why the experiments were carried out at a small load durations.

\section{EXPERIMENTAL TECHNIQUE}

\subsection{Shock-wave generator}

The experiments described here were performed on the Karlsruhe Light Ion Facility (KALIF) [7]. This is a pulse power accelerator delivering a $1.7 \mathrm{MV}, 600 \mathrm{kA}, 50 \mathrm{~ns}$ fwhm pulse to a $2.25 \Omega$ load. Depending on the ion source ("ion diode") employed peak power densities of 0.2 to $1 \mathrm{TW} / \mathrm{cm}^{2}$ can be obtained in a $\sim 10$ $\mathrm{mm}$ diameter fwhm focal spot. At proton ranges of $\sim 5 \mathrm{mg} / \mathrm{cm}^{2}$, specific energies of up to $100 \mathrm{MJ} / \mathrm{g}$ can be deposited in a target at specific power densities of up to $200 \mathrm{TW} / \mathrm{g}$. Because the thermal expansion can follow the bulk energy deposition at sound velocity only, pressures in the 10-100 GPa range build up in the energy deposition zone that drive a compression wave into the adjacent cold material. We used an ion diode providing a peak power density of $0.15 \pm 0.05 \mathrm{TW} / \mathrm{cm}^{2}$ to generate pressure pulses with initial peak amplitudes of up to $30 \mathrm{GPa}$ and $20-30 \mathrm{~ns}$ fwhm durations.

\subsection{Improved line-imaging velocimetry}

For the hydrodynamic beam-target experiments on KALIF, an ORVIS-type laser-Doppler-velocimeter [8] was set up allowing us to measure the target rear surface velocity with a $\geq 200$ ps temporal resolution. It uses a $1 \mathrm{~W}$ single frequency argon ion laser and permits the velocity-per-fringe constant to be varied in multiple steps between $180 \mathrm{~m} / \mathrm{s}$ and $\sim 11 \mathrm{~km} / \mathrm{s}$. The the velocimeter has been modified to provide ID spatial resolution along a measuring line of up to $\sim 8 \mathrm{~mm}$. Compared with the line-imaging VISAR described by Hemsing [9], our instrument uses faster lenses to improve the spatial resolution $(\leq 10 \mu \mathrm{m})$ and to make better use of the laser power, and takes into account that the interefrence fringes in a wideangle Michelson interferometer are localized in the mirror planes. Intermediate imaging onto these planes gives optimum fringe contrast and allows us to easily adjust the magnification scale. Depending on the experimental requirements we operate it either in the VISAR or ORVIS mode [10].

\section{MATERIALS}

Metals selected for testing in the present study were magnesium $\mathrm{Mg} 95$ and molybdenum single crystals. The magnesium Mg95 is "original" cast magnesium which contains (wt.\%) Mg: 99.95; Fe: 0.0004; Si: $0.005 ; \mathrm{Ni}: 0.0007 ; \mathrm{Cu}: 0.003, \mathrm{Al}: 0.007 ; \mathrm{Mn}: 0.01 ; \mathrm{Cl}: 0.005$. The grain size of this cast magnesium is a few millimeters, that, as expected, should allow us to make measurements on separate grains.

Molybdenum single crystal specimens were cut from a 14-mm-diam bar, polished, and then electrochemically etched to remove surface defects. Deformed single crystals were investigated also. These samples were prepared by rolling in the $<110>$ direction of the growth axes along the (001) plane. It has been shown [11] that molybdenum single crystals retain a single-crystalline structure at all stages of plastic deformation as well as under subsequent long-term high-temperature annealing.

\section{EXPERIMENTAL RESULTS}

\subsection{Magnesium}

Figure 1a displays the line imaging ORVIS interferogram of an experiment with a $0.82 \mathrm{~mm}$ thick magnesium sample. Each point of a vertical cross-section of the interferogram corresponds to a point of the measuring line on the sample surface. A vertical displacement of the interference fringes is 

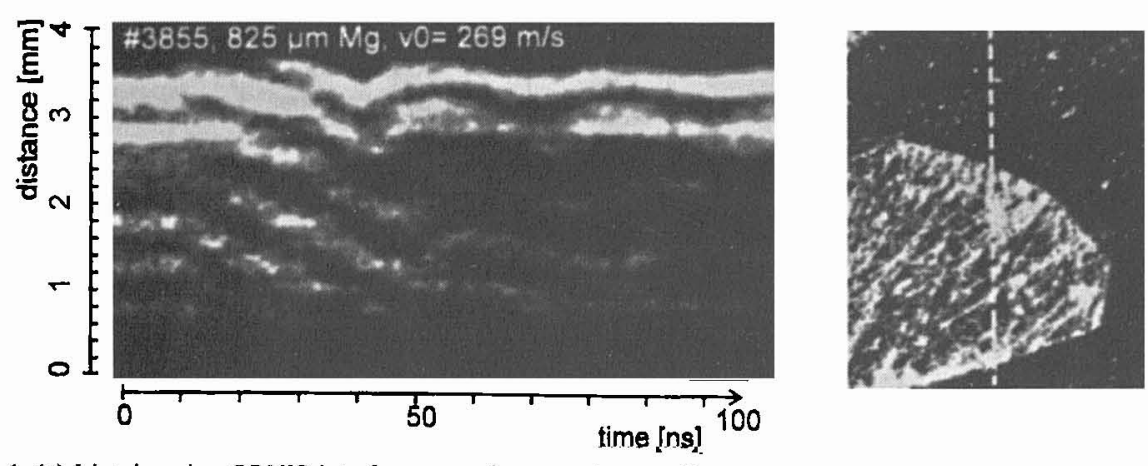

Figure 1. (a) Line imaging ORVIS interferogram of an experiment with a $0.82 \mathrm{~mm}$ thick cast magnesium Mg95 sample. The vertical shift of the interference fringes by one initial fringe distance corresponds to a velocity increment of $269 \mathrm{~m} / \mathrm{s}$. The velocity drop between $10 \mathrm{~ns}$ and $35-45 \mathrm{~ns}$ is the "pullback", the velocity peaks at 40-70 ns represent "spall pulses". Figure 1(b) is a to scale macrograph of the sample, the dashed line indicating the measuring line of the velocimeter.

proportional to velocity increments. Thus, the interferogram directly indicates the velocity histories. The fringe constant $u_{0}$, that is the velocity increment per fringe shift, was $269 \mathrm{~m} / \mathrm{s}$ in this experiment. The field of view of the interferometer included two large grains with different reflectivities, that produced the brightness variations in the interferogram. The power density of the ion beam shows a bell-shaped radial distribution. As a result, the peak shock stress depends on the position.

The interferogram demonstrates typical free velocity histories at spalling. After reflection of the shock compression pulse from the free surface, tensile stresses are generated inside the sample decelerating the free surface. When the peak tensile stress reached the spall threshold, damage begins to accumulate. The stress relaxation at fracture produces a compression wave that shows on the free-surface velocity profile as a velocity increase, the so-called "spall pulse". The velocity pullback, the drop $\Delta u_{f s}$ of the free surface velocity between the peak value and the beginning of the spall pulse, is a measure of incipient fracture strength, or "spall strength", $\sigma^{*}$, of the material. The following velocity oscillations are the result of multiple wave reflections between the free surface and the fracture surface. From the interferogram directly follows that the spall strength in the upper part of the field of view is smaller than that in the lower part.

The evaluation of the CCD-data of the interferograms was done with the VISAR code [12] using two intensity histories (horizontal sections of the interferogram) staggered by $1 / 4$ of the fringe period. The initial jump of the velocity is not resolved on the $100 \mathrm{~ns}$ time scale and has to be determined in separate experiments. On the other hand, the exact knowledge of the peak velocity is not so important for the spall strength measurements because the spall strength does not depend very much on the peak stress. The spall strength of the material was calculated using the following formula [5]:

$$
\sigma^{*}=\frac{1}{2} \rho_{0} c_{b}\left(\Delta u_{f s}+\delta\right)
$$

where $\rho_{0}, c_{b}$ are the initial density and bulk sound velocity of the material, and $\delta$ is a correction for the profile distortion due to the elastic-plastic properties of the material.

Figure 2a shows the variation of the spall strength along the measuring line. The spall strength is changing from point to point in the sample, but, despite of the grain boundary within in the ORVIS field of view ( see fig. $\mathrm{Ib}$ ), there is nowhere a sharp jump in the strength distribution. It is necessary to mention that, under conditions of one-dimensional shock loading of metals with low yield strength, the stress tensor is nearly spherical. In other words, there is no large anisotropy of the loading, and, as a result, there is no jump in strength between grains of different orientation. Of course, the inter-granular boundary in the ORVIS field of view has to be a site of easier nucleation of fracture. but it seems such fine details can be observed only at much larger magnifications. 

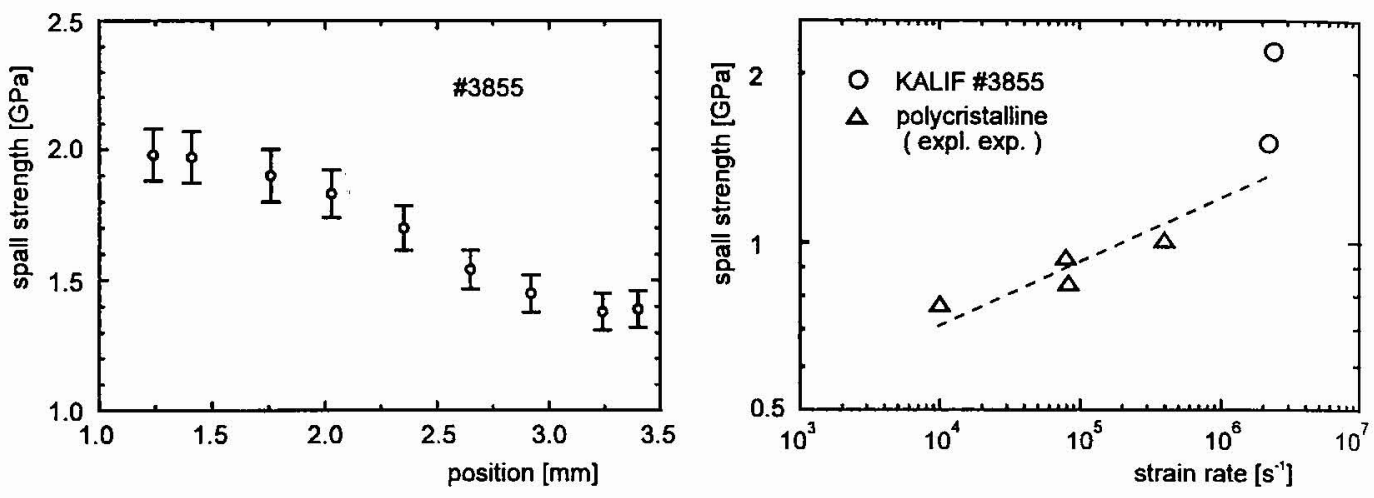

Figure 2: (a) Variation of the spall strength with the position. Data evaluated from the streak record depicted in fig. 1a.

(b) Comparison of these data with the spall strength of polycrystalline magnesium found in explosives driven experiments.

Figure $2 \mathrm{~b}$ shows results of this measurement in comparison with our previous data at lower strain rates [13]. In many previous investigations this dependence is well approximated by a power function over a wide range of strain rates. Figure 3 shows that the new data at highest strain rate deviate upwards from the power dependence. The spall thickness in this experiment varies between $\sim 60$ and $\sim 80 \mu \mathrm{m}$, that is much smaller than the grain size ( 1-2 mm). This means the spall crack crossed the grains, and the spall strength measured corresponds to that of crystals. It has been found earlier $[3,5,14]$ that the spall strength of copper and molybdenum single crystals exceeds that of polycrystalline samples by a factor of $\sim 2$ for molybdenum and $\sim 3$ for copper. Since the deviation of the new data from the extrapolated dependence is not so large, we may suppose that the main spall crack at least partly coincides, in this experiment, with a inter-granular boundary below the sample surface and inclined to that. Thus, both in-granular and intergranular strength were observed and the in-granular strength is as much as twice that on inter-granular boundaries.

\subsection{Molybdenum single crystals}

Figure 3 displays the interferogram and fig. 4 the corresponding free-surface velocity profiles of an experiment with a $0.55 \mathrm{~mm}$ thick molybdenum single crystal. This streak record was done in the line imaging VISAR mode: vertical fringes are lines of equal velocity, the fringe constant being $268 \mathrm{~m} / \mathrm{s}$. The horizontal stripes are due to differences in the reflectivity of the sample surface. In this case the velocity profiles are deduced from the variations of the intensity along a horizontal section of the CCD record. As

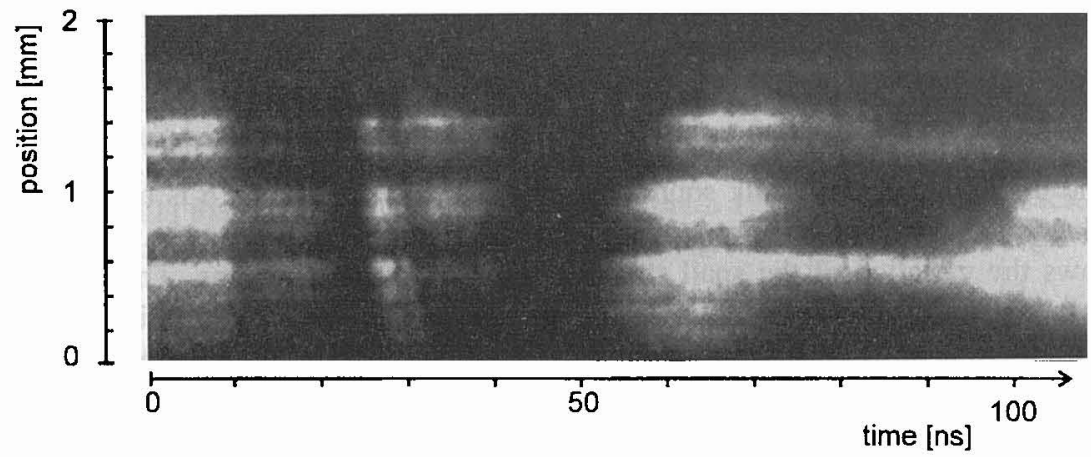

Figure 3: Line-imaging VISAR record using a $0.55 \mathrm{~mm}$ thick molybdenum single crystal. The horizontal stripes are caused by the position-dependent reflectivity of the target. The velocity information is contained in the intensity modulation along a horizontal line. Vertical fringes are lines of equal velocity, the fringe constant being $268 \mathrm{~m} / \mathrm{s}$. 


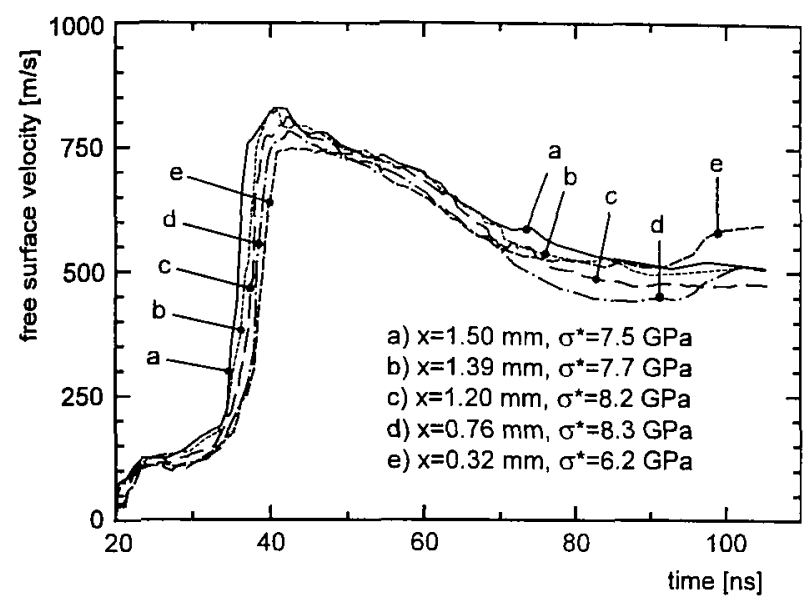

Figure 4: Free surface velocity histories at different positions deduced from the line-imaging VISAR record displayed in fig. 3. The spall pulse is little pronounced or does not show at all.

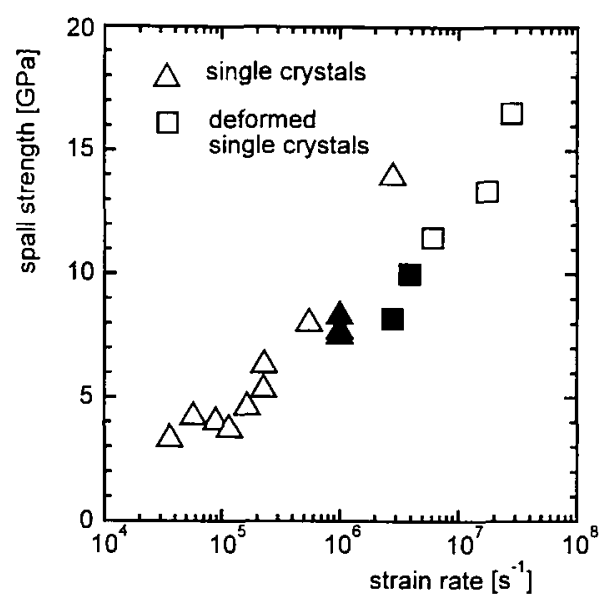

Figure 5: Spall strength of molybdenum single crystals a different strain rates. Open symbols: data from ref. [14]; solid symbols: this work.

a result of the gradient of the power density, the peak stress in the plastic shock wave and the delay time between elastic and plastic waves vary along the measuring line.

Measurements using one single VISAR streak record (instead of up to 4 in order to obtain quadrature componets for an exact evaluation [9] ) do not provide the same accuracy as ORVIS records. On the other hand, the VISAR interferograms display directly the velocity isolines, that permits, for example, to find out immediately any non-uniformity of the spalling process. For example, a region of relatively high spall strength can be observed in the central part of fig. 3 towards the end of the streak as a bright zone due to larger velocity decrease in the incident unloading wave. A certain spread of the spall strength data for metal single crystals was noted in previous investigations $[3,5,14]$. The present experiment shows that the strength can vary from point to point even inside the same single crystal. The evaluation of the interferogram reveals that the spall pulse is little pronounced or even, in points with smaller spall strength, does not show at all. Figure 5 illustrates the scatter of the spall strength data for molybdenum. Two spall experiments with deformed molybdenum single crystals have shown quite different shapes of the spall pulses at insignificant variations of the spall strength. And again, the spall pulse had a reduced slope or even did not form at all at smaller spall strengths.

\section{DISCUSSION}

Fracture is a heterogeneous process which nucleates on defects in the material structure. Dimensions of the potential damage nucleation sites are varied, ranging from the size of inclusions to dislocations and point defects, and, probably, even to thermal fluctuations of the material density. Larger defects are activated at smaller stresses but their amount is less than the amount of smaller defects in the material.

The experiments with magnesium show that a wide spectrum of spall strengths can be realized when the load wave length is less than the grain size of the material. In the experiment presented here, the damage did not nucleate while the reflected tensile wave passed through grains because the tensile stress was not sufficient to activate smaller internal defects. Then the damage obviously easily nucleated when the tensile wave reached the grain boundary below the sample surface that is a large nonuniformity where most weak sites of material are concentrated. When the peak tensile stress reached a sufficient amplitude, initiation of fracture started inside the grains. This is why we observe saturation of the spall strength in fig. $2 \mathrm{a}$. A contribution of the visible grain boundary nearly perpendicular to the sample surface can be probably observed on a smaller scale.

Experiments with both deformed and undeformed molybdenum single crystals show that even these materials are not quite homogeneous. In undeformed molybdenum, the spall strength varies along distances of the order of hundreds of micrometers; for deformed single crystals this value is even higher. Obviously, relatively large nucleation sites are occasionally distributed in these materials, so that they can 
be or can not be in the field of view near future spall plane. When they are activated, stresses are relaxed and, as a result, smaller defects in the next layer are not activated. This means that the total amount of damage sites is not so large. As a result, in the case of activation of scarce larger defects we have a damage rate which is sufficient to form the minimum in the free-surface velocity profile, but is not sufficient to form a sharp spall pulse front.

\section{CONCLUSIONS}

The line-imaging interferometry of free-surface velocity profiles is a way to analyze the uniformity of strength properties of materials. More or less notable oscillations of the spall strength have been recorded with this technique in such different materials as coarse-grain cast magnesium and molybdenum single crystals. In the latter case, small reductions of the spall strength were accompanied by a decreasing acceleration of the fracture process. This phenomenon is qualitatively explained in terms of activation of fracture on relatively scarce larger defects which are occasionally distributed in the material.

$\mathrm{W}$ are planning similar measurements at increased spatial resolution to see the fracture initiation in visible grain boundaries. Line-imaging measurements of the dynamic strength can be especially useful for laminated materials after surface treatment. In some sense, such measurements are similar to microhardness mapping.

\section{Acknowledgment}

This work was supported by the Russian-German Cooperation Program, by the NATO Science Programme, and an INTAS grant. The authors appreciate the continuous interest and support of their joint work by G. Kessler, director of the Institut für Neutronenphysik und Reaktortechnik, FZK Karlsruhe, and by Academician V.E. Fortov, director of the High Energy Density Research Center, Moscow.

\section{References}

[1] Davison L., D. E. Grady, and Shahinpoor M. Eds., High Pressure Shock Compression of Solids - II. Dynamic Fracture and Fragmentation (Springer, New York, 1996).

[2] Curran D.R., Seaman L., and Shockey D.A., Physics Reports 147 (1987) pp. 253-388.

[3] Kanel G.I. et al., "Spallations near the ultimate strength of solids", High-Pressure Science and Technology - 1993, Schmidt S.C. et al Eds. (AIP Press, NY, 1994) pp. 1043-1046.

[4] Kanel G.I. and Utkin A.V., "Estimation of the Spall Fracture Kineticsfrom the Free-Surface Velocity" Profiles", Shock compression of Condensed Matter -1995, Schmidt S.C., and. Tao W.C Eds.,( AIP Press, Woodbury, NY.,1996) pp.487-490 (1996).

[5] Kanel G.I., Razorenov S.V., and Utkin A.V., "Spallation in Solids Under Shock-Wave Loading Analysis of Dynamic Flow, Methodology of Measurements, and Constitutive Factors", in [1], pp. 1-24.

[6] Baumung K. et al., "Hydrodynamic proton beam-target interaction experiments using an improved line-imaging velocimeter", Shock Compression of Condensed Matter-1995, Schmidt S.C., and. Tao W.C. Eds., (AIP Press, Woodbury, NY.,1996) pp. 1015-1018.

[7] Baumung K. et al., Laser and Particle Beams, 14 (1996) 181-209.

[8] Bloomquist D.D. and Sheffield S.A., J. Appl. Phys. 54 (1983)1717.

[9] Hemsing W.F. et al. "VISAR: Line-imaging interferometer", Shock Compression of Condensed Matter-1991, Schmidt S.C. et al. Eds. (Elsevier, Amsterdam, 1992), pp.767-770.

[10] Born M. and Wolf E., Principles of Optics, 6th ed.( Pergamon, Oxford, 1980), p.301.

[11]Pronin L.N. and Aristova I.M., High Temp.-High Press. 22 (1990) 9.

[12] Barker L.M. and Hollenbach R.E., J. Appl. Phys. 43 (1972) 4669.

[13]Kanel G.I. et al. J. Appl. Phys. 79 (1996) 8310-8317.

[14]Kanel G.I. et al. J. Appl. Phys. 74 (1993) 7162-7165. 